\title{
Configurações
}

Revista de sociologia

\section{As memórias "arrumam-se em quadros fixos": a experiência traumática de Solange Matos, narradora de A Noite das Mulheres Cantoras}

Memories "arrange themselves in fixed patterns": Solange Matos's traumatic experience in A Noite das Mulheres Cantoras

Les mémoires «s'aménagent dans des cadres fixes»: l'expérience traumatique de Solange Matos, narratrice de A Noite das Mulheres Cantoras

Patrícia I. Martinho Ferreira

\section{OpenEdition}

\section{Journals}

Edição electrónica

URL: http://journals.openedition.org/configuracoes/3285

DOI: 10.4000/configuracoes.3285

ISSN: $2182-7419$

Editora

Centro de Investigação em Ciências Sociais

Edição impressa

Data de publição: 27 Junho 2016

Paginação: 99-118

ISSN: 1646-5075

Refêrencia eletrónica

Patrícia I. Martinho Ferreira, "As memórias "arrumam-se em quadros fixos": a experiência traumática de Solange Matos, narradora de A Noite das Mulheres Cantoras », Configurações [Online], 17 | 2016, posto online no dia 30 junho 2016, consultado o 01 maio 2019. URL : http://journals.openedition.org/ configuracoes/3285; DOI : 10.4000/configuracoes.3285 
Ferreira, Patrícia I. Martinho - As memórias "arrumam-se em quadros fixos": a experiência traumática de Solange Matos, narradora de A Noite das Mulheres Cantoras. Configurações, vol. 17, 2016, pp. 99-118

\section{As memórias "arrumam-se em quadros fixos": a experiência traumática de Solange Matos, narradora de A Noite das Mulheres Cantoras}

PATRÍCIA I. MARTINHO FERREIRA*

Brown University

\section{Resumo}

Em A Noite das Mulheres Cantoras (2011), Lídia Jorge apresenta-nos uma interessante reflexão sobre os perversos meandros do mundo do show business e da fama conseguida a qualquer preço. Esta reflexão enquadra-se numa macroestrutura narrativa que problematiza a organização da sociedade portuguesa pós-colonial, uma sociedade que recebeu "os restos humanos" de um império de vários séculos. Conjugando aspetos da crítica pós-colonial e dos estudos de trauma e memória, pretende-se analisar neste trabalho o percurso de perda de inocência de Solange Matos (a narradora e personagem principal da narrativa), explorando de que maneira o trauma da experiência colonial se entrelaça com as memórias e os afetos, acabando por interferir na construção da identidade individual.

Palavras-chave: sociedade portuguesa pós-colonial, trauma, experiência traumática, violência, corpo, memória, esquecimento.

\footnotetext{
Abstract

Memories "arrange themselves in fixed patterns": Solange Matos's traumatic experience in A Noite das Mulheres Cantoras In A Noite das Mulheres Cantoras (2011), Lídia Jorge presents an interesting reflection on the perverse intrigues of the world of show business and of fame obtained at any price. This reflection is framed within a narrative macrostructure that problematizes the organization of post-colonial Portuguese society-a society that became the recipient "the human remains" of an empire that endured several centuries. Conjoining aspects of the post-colonial critic and trauma and memory studies, this essay analyzes

* Department of Portuguese and Brazilian Studies, Brown University. Email: patricia_martinho_ferreira@brown.edu.
} 
the course of loss of innocence of Solange Matos (the narrator and main character) in A Noite das Mulheres Cantoras, exploring that sorts out the trauma of the colonial experience is interlaced with the memoirs and the affections, ending for interfering in the construction of the individual identity.

Palavras-chave: postcolonial Portuguese society, trauma, traumatic experience, violence, the body, memory, forgetting.

\section{Resumé}

Les mémoires "s'aménagent dans des cadres fixes " : l'expérience traumatique de Solange Matos, narratrice de A Noite das Mulheres Cantoras

Dans A Noite das Mulheres Cantoras (2011), Lídia Jorge présente une réflexion intéressante sur la perversité des méandres du monde du show business et de la célébrité conquise à n'importe quel prix. Cette réflexion se situe dans une macrostructure narrative qui problématise l'organisation de la société portugaise postcoloniale, une société qui a reçu « les restes humains » d'un empire âgé de plusieurs siècles. C'est en conjuguant des aspects de la critique postcoloniale et des études sur le trauma et la mémoire que nous prétendons analyser dans ce travail le parcours de perte d'innocence de Solange Matos (la narratrice et le personnage principal du récit). Nous explorerons la façon dont le trauma de l'expérience coloniale s'entrelace avec la mémoire et les affects et finit par interférer dans la construction de l'identité individuelle.

Mots-clés : société portugaise postcoloniale, trauma, expérience traumatique, violence, corps, mémoire, oubli.

Em A Noite das Mulheres Cantoras, o décimo romance de Lídia Jorge, publicado em 2011, a autora apresenta-nos uma ampla reflexão sobre os meandros da cultura do espetáculo. Este mundo, projetado na narrativa através da expressão "império minuto", traz consigo associadas as temáticas do imediatismo, do esquecimento, assim como das rápidas transformações sociais e dos efeitos perversos da fama conseguida a qualquer preço. Esta reflexão enquadra-se numa macroestrutura narrativa que remete para as vivências da sociedade portuguesa colonial e pós-colonial, uma sociedade que recebeu, na segunda metade da década de 70, "os descendentes dos pedaços de um velho império" $(17)^{1}$ de vários séculos. Com efeito, ao mesmo tempo que propõe uma reflexão crítica sobre a efemeridade e o imediatismo típicos da indústria do show business, Lídia Jorge retoma neste romance a sua preocupação com a história e a identidade portuguesas, sublinhando, uma vez mais, a necessidade de não esquecermos, ou seja, de percebermos que o esquecimento não é fatalmente a única "lei que nos rege" (11) quer enquanto indivíduos, quer enquanto sociedade. Por outras palavras, tanto o

1 Todas as citações do romance em análise serão identificadas apenas através do número de página. 
esquecimento imposto pelos imperativos do "reino do efémero" (uma expressão usada no livro como sinónimo de "império minuto") quanto o esquecimento do nosso passado colonial devem ser combatidos criticamente.

A trama deste romance é aparentemente simples. Temos cinco jovens que, no final dos anos 80 (mais especificamente nos anos de 1987 e 1988), se reúnem para formar uma banda musical com o ambicioso objetivo de abalar o panorama musical português. Vinte e um anos mais tarde, Solange Matos (a letrista do grupo) decide contar a história desse projeto, expondo algumas verdades que o tempo deixou escondidas e expondo, sobretudo, a perversa personalidade de Gisela Batista, a líder da banda e a única que, passados todos esses anos, continua imersa nas redes da cultura do espetáculo.

A problemática em torno do esquecimento e da memória é central nesta narrativa, e a escritora parece enfatizar que só através da memória podemos reavaliar criticamente o passado, entender o presente e antecipar o futuro. No caso deste romance, a reavaliação do passado é feita pelo menos a dois níveis. Num nível mais óbvio, e que se prende com a estrutura do próprio livro, essa reavaliação é feita através da junção de duas sequências narrativas diferenciadas. Ainda que a voz da enunciação seja a mesma - a de Solange Matos, a intenção subjacente a estes dois relatos, apresentados paralelamente, é diferente. Na primeira sequência, intitulada "Noite perfeita", a narradora centra-se no evento que decorre no Tivoli e que reúne, em prol do sucesso de Gisela, as cantoras vinte e um anos depois da formação e dissolução do grupo, reproduzindo a perspetiva desta última sobre os eventos passados. $\mathrm{Na}$ segunda, a narradora ocupa-se da sua própria versão dos acontecimentos, entrevendo-se neste seu ato de contar uma genuína necessidade de repor a verdade sobre as situações vividas duas décadas antes. Num nível menos óbvio, mas latente, o passado questionado e reavaliado é o passado coletivo, o passado de um país colonial que tardou a fazer a descolonização e ao qual o leitor tem acesso através de experiências individuais - as experiências das cinco cantoras da banda.

No artigo intitulado "Literatura, memória, resistência: breves apontamentos em tempo de crises" (2012), Paulo de Medeiros reflete sobre o contexto histórico-social da atualidade europeia e, em particular, da portuguesa, bem como sobre a possibilidade de a literatura funcionar como espaço de reavaliação do passado, de construção do presente e de projeção do futuro. Efetivamente, Medeiros explica que vários autores portugueses contemporâneos (como António Lobo Antunes, Lídia Jorge, Dulce Maria Cardoso e valter hugo mãe) têm vindo a oferecer "possibilidades de contestar a situação atual ao insistir[em] na reflexão sobre o passado imperial e colonial e os modos em como esse passado - ainda bem recente - continua a assombrar a sociedade portuguesa, e não só" (218). O escopo do artigo de Medeiros é alargado e remete para o trabalho de memória e de questionamento do passado feito no âmbito das várias literaturas escritas em língua portuguesa, porém, o que aqui 
nos interessa são as suas reflexões sobre o caso específico dos autores portugueses. Medeiros destaca, a este propósito, o contributo que as narrativas literárias centradas na realidade portuguesa podem dar ao debate sobre a condição pós-imperial da Europa, afirmando que o fazem através do modo "como combinam questões pós-coloniais com aspectos de trauma, individual e colectivo” (222). Numa sociedade que precisa de construir um futuro mais digno, é imperativo, insiste o autor, "estudar as questões de traumas individuais e colectivos referentes ao passado político do país e a forma em como ele condicionou não só o quotidiano pessoal como a própria construção da identidade nacional” (222). Medeiros chama a atenção, deste modo, para a "necessidade de conjugar aspectos da crítica e teoria pós-colonial aos estudos de trauma e de memória” (222) no sentido de melhor reavaliar o passado de forma crítica e, consequentemente, diremos nós, melhor entender as propostas narrativas de alguns autores contemporâneos, como Lídia Jorge. Paulo de Medeiros afirma que o passado colonial português continua de certa maneira a "assombrar" o presente da sociedade portuguesa e é justamente essa ideia que pretendo explorar neste trabalho.

Em Trauma and Survival in Contemporary Fiction (2002), Laurie Vickroy explica que as narrativas sobre trauma desempenham uma função importante ao explorarem a questão da memória e do esquecimento nos contextos das relações sociais e psicológicas. A experiência traumática e a sua representação têm sido, por isso, um dos tópicos trabalhados nos últimos tempos e as análises pós-coloniais dos custos psicológicos da colonização e do racismo ocupam um papel relevante em algumas destas narrativas. A autora declara, igualmente, que o envolvimento e a adesão emocional do leitor acontecem de forma natural porque estas narrativas levantam questões sobre a subjetividade e a habilidade de lidar com a perda, mas também porque levantam questões e dilemas que nos confrontam com os nossos próprios medos e porque, em última análise, confrontam a sociedade com os indivíduos traumatizados.

O percurso da perda de inocência ${ }^{2}$ de Solange Matos, a narradora de $A$ Noite das Mulheres Cantoras, é um exemplo evidente tanto da "assombração" de que Paulo de Medeiros fala, quanto da necessidade de confrontar a sociedade portuguesa com os traumas dos seus cidadãos. Nascida em Moçambique, aos seis anos de idade, Solange é obrigada a fugir com os pais no momento em que a ex-colónia portuguesa conquista a sua independência, a custo de uma longa guerra colonial. Durante essa travessia, Solange vive uma situação que a marcará profundamente e que diz respeito ao momento em que o pai se prepara para cometer um ato de extrema violência sobre um jovem negro de quem dizia ser o seu aluno preferido. Leia-se a passagem em que essa situação é descrita ao pormenor:

2 Referindo-se a Eva Lopo, a protagonista de A Costa dos Murmúrios, Maria Graciete Besse nota que a perda da inocência é ilustrada, por vezes, pela "revisitação da memória individual e coletiva" (123). O caso de Solange Matos é um outro exemplo disso mesmo. 
Muita coisa se esfumou do que se passou à sombra dos Montes Namuli [...]. Mas lembro-me da nossa saída em fuga pela estrada do Gurué afora, e do camião de caixa aberta onde transportávamos as malas cobertas por um oleado verde.

Lembro-me que à saída de Gurué o meu pai descobriu que não fugíamos sozinhos, que o aluno dilecto se tinha instalado entre o oleado e as malas. Lembro-me de ver o meu pai a saltar da cabina, de se dirigir à carroçaria e de expulsar o aluno que não sabia ler o x. Lembro-me de retomarmos o caminho e de vermos que duas mãos continuavam penduradas no taipal traseiro. Lembro-me de o meu pai pisar com a ponta das suas botas os dedos do aluno dilecto, de as mãos do aluno resistirem ao impacto das solas, de o meu pai reentrar na cabina e pegar na catana que levávamos sob o assento, disposto a cortar as mãos do aluno dilecto agarradas ao taipal, e depois só me lembro de ver, atrás do nosso camião, e de a sua figura ir minguando, até que se fez uma curva e o homem e a estrada desapareceram de todo. Mas não sei concluir sobre esta circunstância a não ser que ela se incorporou no meu corpo, que ficou atada a ele, presa por nervos e ligamentos, como uma perna, um braço, um órgão. Levei-a comigo quando entrei para a escola e depois para a universidade, fez comigo todo o tipo de provas e exames finais, viajou com a minha pessoa por onde quer que eu fosse [...]. (51-52, destacados nossos)

Este episódio em que o pai, de catana em riste, se dispõe a cortar as mãos do jovem negro a quem tinha ensinado a ler vai ser central no percurso de busca ontológica de Solange, uma vez que é revivido como uma experiência profundamente traumática.

Na introdução a Trauma: Explorations in Memory (1995), Cathy Caruth explica que ser traumatizado é ser possuído e perseguido por uma imagem ou evento, o que faz com que o indivíduo traumatizado faça parte de uma história que não é capaz de apreender e compreender na totalidade. Deste modo, um trauma é uma resposta "sometimes delayed, to an overwhelming event or set of events, which takes the form of repeated, intrusive hallucinations, dreams, thoughts or behaviours stemming from the event" $(4)^{3}$. Esta patologia consiste, como explica a autora, "solely in the structure of the experience or reception: the event is not assimilated or experienced fully at the time, but only belatedly in its repeated possession of the one who experiences it" $(4)^{4}$. A descrição de Caruth aplica-se justamente à experiência de Solange, na medida em que esta jamais esquece as mãos do jovem negro que, agarradas ao taipal, tentavam acompanhar o camião em fuga. O ato de violência que o pai estava disposto a exercer sobre alguém de quem aparentemente gostava acompanha Solange como se fosse mais um membro do seu corpo e esse membro fosse indispensável

3 Tradução: "resposta, às vezes, atrasada, a um evento avassalador, ou a um conjunto de eventos, que pode assumir a forma de alucinações, sonhos, pensamentos ou comportamentos repetidos e intrusivos decorrentes do evento". Todas as traduções neste ensaio são nossas.

4 Tradução: "unicamente na estrutura da experiência ou da receção: o evento não é assimilado ou experimentado plenamente no momento em que acontece, mas só mais tarde na possessão repetida de quem o experienciou". 
à sua sobrevivência. Esta relação dialógica entre o "corpo" da narradora e a "circunstância" por si vivida durante a "fuga pela estrada do Gurué afora" vai ser lembrada repetidamente ao longo da sua vida, e essa lembrança vai acompanhá-la para todos os lados como um fantasma que a assombra e a pressiona, como uma imagem de difícil explicação e entendimento, enfim, como um evento traumático. Se voltarmos ao fragmento acima citado, veremos que essa experiência é, em termos linguísticos, expressa pela incisividade das frases curtas, pela plasticidade do verbo esfumar-se, pelo uso repetitivo do verbo lembrar-se e, ainda, pela abundância dos verbos de movimento (saltar, reentrar, ir minguando, etc.). Relevante é também o duplo uso da conjunção adversativa - mas - que marca, num primeiro momento, a oposição entre o não lembrar e o lembrar e, num segundo, entre a memória e a compreensão dessa memória.

Sente-se no relato de Solange uma profunda e incontrolável urgência de regressar ao passado, como se aquela "circunstância" lhe tivesse "ficado colada ao corpo de forma tão renitente quanto a imposição física de um membro, ou de uma víscera" (32) e o voltar a ela fosse, para si, uma inevitabilidade que a sua vontade e a sua racionalidade não conseguem controlar. A inscrição daquele episódio do passado no seu próprio corpo é, como se vê, altamente expressiva, tanto porque mostra que um episódio violento vivido na infância se intromete de forma contínua no presente, como porque reitera a impossibilidade do esquecimento, sublinhando a violência envolvida naquela situação. Apesar de a violência do pai não ter sido dirigida ou exercida sobre ela, Solange guardou essa violência como se fizesse parte do seu próprio corpo, como se fosse uma víscera, a parte mais íntima de si própria. Tal como Laurie Vickroy explica "living history and trauma in the body not only demonstrates some of the most painful aspects of enduring and surviving traumatic situations, but also gives readers a sense of the violations experienced by individuals as larger forces intrude on them" (2002: 223) ${ }^{5}$. Essa violência representa, assim, uma força intrusa que se impõe sem autorização e que constitui o núcleo da situação traumática.

É importante notar ainda que essa "circunstância" do passado paira na vida de Solange de forma latente, perseguindo-a constantemente e influenciando a sua maneira de ser e agir. Dominik LaCapra define os eventos traumáticos que exercem uma força avassaladora na vida de um indivíduo como "hauntingly possessive ghosts" (2001: xi) ${ }^{6}$. Esta definição de LaCapra perpassa todas as descrições e alusões que a narradora faz relativas ao impacto daquela circunstância vivida a caminho de Joanesburgo, mesmo que a narradora não use explicitamente a palavra fantasma. Leia-se este breve exemplo: "Eu não

5 Tradução: “viver a história e o trauma no corpo não só demonstra alguns dos aspetos mais penosos de ter sobrevivido ou resistido a situações traumáticas, mas também dá aos leitores uma noção das violações sofridas por indivíduos quando forças maiores se intrometem nas suas vivências".

6 Tradução: "fantasmas assustadoramente possessivos". 
falava do assunto, mas essa travessia vivia comigo de manhã à noite, marcava o meu ritmo e a minha crença, pintava de cores impressivas a minha reserva e a minha juvenil brutalidade" (32-33).

A “circunstância” traumática vivida na travessia do Gurué invade (mesmo que não fale sobre ela) o presente da narradora, sem que esta o possa evitar. E tal irrupção de uma temporalidade na outra é vivida como uma forma de posse ou assombração. A vivência de Solange Matos ilustra precisamente esta relação temporal não linear com o passado, sendo a associação entre o episódio da travessia e a sua relação com Murilo Cardoso um exemplo evidente. Ao corporizar todas as certezas que Solange não consegue ter perante a vida, este jovem (com a sua intransigência e o seu idealismo político) funciona como um gatilho que, por um lado, despoleta a violência que a assombra desde criança, e por outro, reitera a necessidade inexorável de ruturas. Assim, é a imagem das "mãos agarradas ao taipal" que lhe vem à memória quando Murilo a adverte dos perigos que a sua relação com a Gisela Batista lhe traria no futuro (52) ou, ainda, quando ela própria, perante a antevisão do sucesso que a sua carreira como letrista e cantora lhe proporcionaria, justifica a impossibilidade de continuar a relacionar-se com Murilo?.

O impacto emocional daquela cena de violência na vida de Solange é, com efeito, traduzido através da dilatação do tempo cronológico e da imagem de um corpo paralisado e hesitante face a uma situação que exige uma resposta imediata. Como Anne Whitehead afirma "In its negative aspect, repetition replays the past as if it was fully present and remains caught within trauma's paralysing influence" (2004: 86) ${ }^{8}$. Essa paralisação que decorre da invasão do presente pelo passado é experienciada por Solange não só quando esta, perante o desafio das irmãs Alcides de ser a letrista de uma nova banda, se sente incapaz de dar uma resposta assertiva e apenas aceita o convite para contrariar Murilo, mas também quando se vê questionada por Gisela Batista sobre as suas ambições para o futuro. Em ambos os casos é a sua capacidade de decisão e ação que é posta em causa'.

A sensação de flutuar entre o passado e o presente é constante na vida de Solange e tal flutuação manifesta-se na narrativa quando esta nos dá conta, por

7 Leia-se: "Murilo tinha passado a ser duas mãos coladas ao taipal de um camião de caixa aberta. O mundo miniatural estava cheio delas, as de Murilo eram apenas mais duas. E eu ainda ouvia o meu pai dizer, quando recordava a nossa fuga, que só dispondo de uma vida nunca daremos resposta àqueles que exigem que nos separemos em partes inseparáveis. Não podemos ser dois mundos. Era o que a imagem do meu pai me dizia, de catana levantada, disposto a cortar as mãos do aluno dilecto. Um assunto sem solução que regressava, de novo, para resolver o caso de Murilo" (170).

8 Tradução: "No seu aspecto negativo, a repetição reproduz o passado como se estivesse totalmente presente e continua enredada na influência paralisante do trauma.”

9 Leia-se: "Paralisada. Como muitas vezes sucedia, a imagem dos campos enlameados do meu pai vinha ter comigo, prendia-me ao chão, os seus ruminantes conduziam-se para os sítios da prudência, o tempo dilatava-se na minha frente em todas as direcções e eu pensava em vários dados em simultâneo." (43) E "Eu estava paralisada, e deveria dar-lhe a imagem de uma criatura em plena desorientação, uma rapariga afundada em silêncio e estupor [...]” (61). 
exemplo, da invasão da infância (tanto da infância passada em Moçambique, como no interior de Portugal, já depois do regresso apressado) nas suas vivências como adolescente e jovem adulta. A este respeito, o percurso emocional, mental e comportamental de Solange pode enquadrar-se na argumentação de Inge Wimmers sobre a natureza e a função das emoções. Na senda de Martha Nussbaum, que chama a atenção para a importância das narrativas no estudo das emoções, Wimmers explica que as emoções são uma espécie de estrutura cognitiva cujas fundações podem ser encontradas muito cedo na vida, sendo determinantes na vida adulta: "the 'geological upheavals of thought' that constitute the adult experience of emotion involve foundations laid down much earlier in life, experiences of attachment, need, delight, and anger. Early memories shadow later perceptions of objects, adult attachment relations bear the traces of infantile love and hate" (2003: 6) ${ }^{10}$. No percurso de Solange essas fundações remetem, sem dúvida, para as suas vivências coloniais. É importante lembrar igualmente que a evocação de experiências traumáticas ou, simplesmente, de experiências emocionais negativas se repete independentemente da vontade da pessoa implicada na situação em causa, tal como Caruth (1996: 2) explica e Solange ilustra: “essa travessia vivia comigo de manhã à noite (...). No lugar onde deveriam alinhar-se abstracções escolares (...) alojavam-se concretos apanhadores de chá vergados sob cestos, o cheiro das folhas delidas sob o efeito da secagem" (33).

A esta sensação acrescem as dificuldades de falar sobre o passado ("Nunca falávamos de nós" 30) e de tomar as rédeas da sua vida, como se Solange fosse apenas uma peça dentro de um vasto puzzle com regras que não foram criadas por ela (a ideia do pai como "o narrador da [sua] vida” ilustra precisamente esta falta de agência a que Solange alude). Essas dificuldades expressam-se na contradição existente entre a crença incutida pelos pais na não inevitabilidade do destino - "eu tinha recebido a ideia de que o destino é uma oferta que o presente faz ao futuro, e não o contrário" (30) -, e o sentimento de que a vida é movida inelutavelmente por um carro conduzido por dois cocheiros, isto é, forças que não controla ${ }^{11}$.

Os estudos mais recentes em torno das teorias relacionadas com o trauma e as ficções que se centram em vivências traumáticas apontam várias técnicas linguísticas usadas pelos autores para traduzir o trauma e o impacto da situação traumática perante os leitores. De acordo com Anne Whitehead, essas

10 Tradução: “as ‘convulsões geológicas do pensamento' que constituem a experiência emocional dos adultos envolvem fundações estabelecidas muito mais cedo na vida, experiências de apego, necessidade, prazer e raiva. As memórias de infância ensombram perceções posteriores dos objetos, relações de apego em adultos mostram os traços do amor e ódio infantis."

11 Imagem que a narradora explica desta maneira: "Também morava uma espécie de cautela, uma lentidão qualquer, a ensinadela demasiado temporã de que a vida é levada por dois carros e um deles não o conduzimos nós. Um cocheiro encapotado leva metade da nossa vida para onde ele próprio entende. Soubera-o demasiado cedo. Essa reserva dividia-me em duas, e uma parte vigiava a outra, puxada por dois cocheiros adversos. Um deles proibia-me de falar desse passado" (33). 
técnicas formais aproximam-se frequentemente da sintomatologia do trauma: "Novelists have frequently found that the impact of trauma can only adequately be represented by mimicking its forms and symptoms, so that temporality and chronology collapse, and narratives are characterised by repetition and indirection" (2004: 3) ${ }^{12}$. Essas técnicas são essencialmente quatro: a fragmentação da narrativa, o colapso da temporalidade, as intertextualidades e a repetição. Um exemplo claríssimo de todas elas encontra-se na extensíssima obra de António Lobo Antunes que pode, sob várias óticas, ser analisada e explorada a partir da questão do trauma. Note-se que a repetição pode operar ao nível da linguagem, das imagens e da trama, acabando por imitar os efeitos do trauma porque "it suggests the insistent return of the event and the disruption of narrative chronology or progression. Repetition is inherently ambivalent, suspended between trauma and catharsis" (Whitehead, 2004: 86-87) ${ }^{13}$. No caso de Lídia Jorge, esta questão não surge como o eixo central dos seus livros, mas ganha uma relevância inegável na narrativa de $A$ Noite das Mulheres Cantoras. E isso parece acontecer sobretudo pela técnica da repetição, em particular, a nível da construção psicológica da narradora.

Em Writing History, Writing Trauma, Dominik LaCapra alerta para a importância dos estudos sobre o trauma quando se pretende fazer uma apreensão crítica do século XX. O historiador explica também que há diferentes tipos de memórias e, portanto, várias formas de lembrar e escrever o passado e as situações traumáticas. À semelhança de outros autores, LaCapra defende que é necessário interpretar e escrever a história fora do espartilho da objetividade. Baseando-se em termos usados por Freud, LaCapra descreve dois processos que agem em conjunto, embora de forma diferente, no que toca à relação com um passado traumático. O primeiro processo - "acting-out" - está relacionado com a repetição, em particular com a repetição compulsiva, ou seja, a tendência para se repetir algo compulsivamente e, quase sempre, num estado de melancolia interminável. O segundo - "working-through" - descreve o esforço que se faz para ganhar distância crítica relativamente ao momento traumático, ao mesmo tempo que se distingue passado, presente e futuro. Este processo pode, deste modo, ser definido e encarado como uma espécie de estado de luto. Não se trata de esquecer o passado, mas de contextualizá-lo e seguir em frente. Ao confrontar estes dois processos, LaCapra sublinha que eles estão intimamente relacionados, mas que é fundamental encará-los como forças compensatórias, assim como reconhecer que há possibilidades de "working-through that do not simply loop endlessly back into the repetition compulsion or go to the (illusory)

12 Tradução: "Os romancistas têm visto frequentemente que o impacto do trauma só pode ser adequadamente representado através da imitação das suas formas e sintomas, de modo que a temporalidade e a cronologia colapsam, e as narrativas são caracterizadas por repetição e formas indiretas.”

13 Tradução: "isto sugere o insistente retorno do evento e a perturbação da cronologia ou da progressão narrativas. A repetição é inerentemente ambivalente, em suspensão entre o trauma e a catarse.” 
extreme of total transcendence of acting-out, or total transcendence (or annihilation) of the past" (2001: 150) ${ }^{14}$. Embora LaCapra sublinhe que, em muitos casos, para a vítima "it may be impossible fully to transcend acting-out" $(152)^{15}$, a experiência traumática deve, na sua ótica, ser trabalhada com vista a obter-se uma compreensão global dessa experiência e a encontrar-se formas para lidar com ela conscientemente ${ }^{16}$.

No caso da obra aqui em análise, o percurso da personagem-narradora parece aproximar-se mais do que LaCapra chama de "acting-out", na medida em que o seu dia a dia é invadido constantemente pelas imagens do passado, como temos vindo a dizer, sem que esteja explícita a vontade de compreender essas imagens e distanciar-se delas. Muito pelo contrário, essas imagens mostram-se muito vivas e muito encrostadas no corpo da narradora, como se constituíssem uma força omnipresente incapaz de ser domada. Ao longo da narrativa, encontram-se vários momentos em que esses fantasmas do passado ressurgem no quotidiano de Solange ativados por alguma situação ou sentimento e sem que possam ser controlados. Isso acontece, como já foi dito acima, em quase todas as situações em que a narradora interage com Murilo, mas também em muitos dos momentos que ela vive na garagem da Casa Paralelo, local onde se concentram os sonhos e as exigências de Gisela Batista, a líder do grupo. É, aliás, durante a tarde em que decorre o primeiro ensaio que, quando Solange se apercebe das dificuldades de conciliar desejos e realidade, a sua mente se deixa invadir pelas imagens e sentimentos do passado. Perante a tenacidade de Gisela em construir uma banda de sucesso, enfrentando todas as contrariedades, Solange encontra refúgio nas suas memórias, acabando por se distanciar do momento presente, pelo menos mental e emocionalmente: "Nessa tarde, os episódios da travessia desde África várias vezes me visitaram, desde o Expulsá-los-emos até ao camião conduzido pelo meu pai e um homem correndo atrás, sem hipótese de nos alcançar” (77, itálico do original).

A narrativa de Solange caracteriza-se por um profundo pessimismo, distanciamento e melancolia. Uma vaga noção de perda percorre as suas observações, tanto sobre a experiência colonial da família em África, quanto sobre a sua experiência como jovem universitária na Lisboa em transformação social e cultural dos anos 80 . O agudíssimo espírito de observação desta narradora é, curiosamente, atribuído por si própria a essa experiência num tempo remoto em que a desconfiança (do desconhecido? do africano?) fazia parte da ordem

14 Tradução: "working-through que não se revolve simples e indefinidamente em torno da repetição compulsiva ou desemboca no (ilusório) extremo de total transcendência do acting-out, ou mesmo total transcendência (ou aniquilação) do passado.”

15 Tradução: "pode ser impossível ultrapassar totalmente o acting-out".

16 Leia-se a argumentação de LaCapra sobre este processo. O autor distancia-se de Caruth, dizendo que a posição desta autora aproxima o trauma do sublime e de uma espécie de sacralização. Ao colocar a ênfase na repetição compulsiva, parece que Caruth tem uma visão menos positiva no que respeita à possibilidade de "working-through" (LaCapra, 2004: 121). 
do dia. Leia-se: "Eu conhecia a raiz do meu vício de observação, uma certa crueldade, tinha-a trazido do fundo dos campos, dos tempos imemoriais da desconfiança comandada pela aparência dos forasteiros que batiam à porta sem aviso" (111). Lembramos aqui a questão da "desconfiança" porque talvez se possa perceber, a partir dela, as eventuais razões pelas quais a travessia do Gurué emerge no corpo e na vida de Solange como um trauma, como uma assombração que a persegue durante toda a vida.

Quando Solange descreve o acidente e o desinteresse do seu pai pela caça, bem como o apreço deste por, nas horas vagas, ensinar a ler os apanhadores de chá, menciona a preferência dele por um dos alunos e, logo a seguir, relata a dúvida que esse tal aluno colocou ao professor "num domingo de manhã". A dúvida era aparentemente simples, esse aluno pronunciava e lia bem todas as letras do abecedário exceto a letra $x$, que vinha integrada na frase "Expulsálos-emos até a sua última pegada" (50). Ensinado o som do $x$ e treinada a leitura da frase com o aluno (ao que se seguiu um gesto de agradecimento por parte deste através da oferta de "uma algibeira cheia de caju torrado"), o pai de Solange compreendeu que a luta pela independência iria acabar por vencer e que os colonos poderiam ser expulsos a qualquer momento, tal como o papel trazido pelo aluno prenunciava. Restava à família deixar Moçambique com a maior brevidade possível e, enquanto isso não acontecia, preparar-se para viver num ambiente hostil. Por isso, no momento da fuga, confrontado com as mãos do aluno preferido agarradas ao taipal do camião que conduzia, o pai de Solange pôs de lado o afeto que sentia por aquele aluno e deixou que o medo e a luta pela sobrevivência se apoderassem de si e dos seus atos. A contradição que essa atitude de desconfiança e medo envolve é transmitida ao leitor através das reflexões de Solange sobre a inconciliação entre um ato de amor e um ato de traição. Inconciliação essa que vai constituir o núcleo da vivência traumática que se impregna no corpo da narradora. Com efeito, Solange é incapaz de conciliar forças contraditórias e trágicas como, por um lado, os pais a dançar felizes e, por outro, os pais dispostos a cortar as mãos de um jovem negro. A sua conclusão é desconcertante e explica, de certa forma, a razão pela qual aquele ato de violência protagonizado pelo pai compromete permanentemente o seu presente e futuro. Opondo-se às certezas e ao espírito idealista e inconformista de Murilo, Solange declara: "Como haveria [Murilo] de relativizar os factos se caminhasse como eu, com duas imagens contraditórias ao ombro. Numa delas, os meus pais rodopiavam abraçados, e era de júbilo, na outra estavam dispostos a cortar as mãos de um homem, e era trágico. Prova de que é tão impossível gerir o amor quanto o ódio, quando tomados em absoluto" (52).

A contradição que estas imagens inconciliáveis encerram é profundamente impactante na vida de Solange, sobretudo porque a incompatibilidade entre amor e ódio se desdobra na ideia de que viver e sobreviver implica necessariamente trair. Tal disposição mental e emocional perante a vida emerge na 
narrativa quando Solange é confrontada com certas atitudes ou acontecimentos quotidianos, assim como quando relata o seu relacionamento com os outros. A assertividade das suas observações a este respeito é notória. Destacam-se dois exemplos, o primeiro encontra-se quando Solange, ao explicar por que motivo omite de Gisela a sua relação amorosa com João de Lucena, declara: "a traição é uma condição tão comum quanto sobreviver" (181). E o segundo encontra-se quando Solange (confrontada com as pressões de Gisela relativamente ao excesso de peso e, na sua visão, à falta de empenho das restantes cantoras da banda) confessa compreender as exigências da maestrina, embora não as siga: “[Gisela] já não pronuncia as palavras, mas nós ouvimo-las e conhecemo-las. Eu dou-lhe razão, estou com Gisela, compreendo-a, ainda que atraiçoando-a. Atraiçoando-a, sem remédio" (183).

A perspetiva de uma vida nova como letrista e cantora da banda Apocalipse e como namorada de João de Lucena, faz com que Solange deseje desprender-se da paisagem liliputiana em que o seu passado se transformou. Face às possibilidades de sucesso como letrista e ao amor que nutre por Lucena, o passado transforma-se num mundo miniatural e Solange entrevê a possibilidade de um renascimento ${ }^{17}$.

O que Solange acaba, no entanto, por ser forçada a descobrir, ao longo do ano de 1988, é que aquelas possibilidades de sucesso e de amor vêm manchadas de morte e traição - a morte de Madalena Micaia, a homossexualidade não assumida de Lucena e os segredos de Gisela. Em diálogo consigo mesma, depois de ter percebido que o seu amor por Lucena não era correspondido, do mesmo modo, o passado que se transformara em miniatura reemerge nos pensamentos de Solange como se nunca tivesse realmente perdido o seu tamanho real. O facto de as suas expectativas de uma vida a dois com Lucena não se concretizarem e, sobretudo, o facto de ele ter traído a confiança dela, omitindo as suas verdadeiras intenções, obriga-a a reconhecer que o que realmente a identifica como pessoa não é o que ela é ou faz perante os outros, mas o passado dorido e contraditório que carrega consigo:

A minha própria identidade interessava para alguém? O meu nome? As minhas letras? Aquilo que eu trazia às costas de mais importante não era, afinal, a imagem do meu pai levantando a arma do inimigo contra o seu amigo? Uma catana estrangeira na sua mão, pronta a decepar os dedos do seu aluno dilecto? Essa imagem ameaçadora que eu temperava com o som manso da Balada do chazeiro, e com as duas eu equilibrava o mundo? E no entanto, esse traço corpóreo que me identificava, meu verdadeiro gene, por acaso transparecia em alguma das feições do meu rosto? Não sei quando eu tinha aprendido a desconfiar da certeza,

17 Leia-se: “Uma série de acontecimentos estão a cavar uma fundação inexplicável na minha nova alma. O Sobradinho, o tempo das vacas, da ramada, dos melros, já é apenas um longínquo cimento que paira ao fundo de umas estradas. África, o Monte Namuli e a sua senda, um mundo miniatural que se apaga. Agora a minha vida mudou" (208). 
a aceitar o pouco, o pobre, a parte, o pequeno, o lateral, o duvidoso, o humilde, o restante, não sei quando. Isso identificava-me. (282, negritos nossos)

As antíteses entre amigo e inimigo, amor e ódio, viver e atraiçoar geradas pela dolorosa travessia do Gurué vão reaparecer na trágica história de Madalena Micaia, demonstrando que tanto o jovem negro, como Madalena Micaia (a melhor voz do grupo, que tinha como alcunha "The African Lady") não têm espaço numa sociedade pós-colonial que não acomoda nem respeita as diferenças, uma sociedade que não fez o seu trabalho de reflexão coletiva relativamente à perda do império e à receção e integração de uma população muitíssimo heterogénea no período pós-25 de abril de 1974. É com um acentuado pessimismo que Solange afirma: "Sempre haverá duas mãos agarradas ao taipal de um camião que o condutor em fuga conduz, à frente da guerra. Já percebi que viver é atraiçoar. Sobreviver implica trair. Devo aprender com Madalena Micaia” (184).

A ideia da narradora de que as suas memórias se "arrumam em quadros fixos" (79) e de que é a partir deles que se pode ir acedendo ao passado relaciona-se, como já dissemos, com o movimento de repetição mental e emocional que Solange vive e constantemente a transporta para o passado, mas também com a sua própria criação artística. As suas letras decorrem de uma inspiração poética que privilegia as memórias que o seu corpo carrega. De facto, talvez não seja por acaso que a descrição que Solange faz do seu ato de escrita seja feita com referências corporais, tal como a descrição da imagem que a persegue desde o seu regresso de África ${ }^{18}$.

Os estudos académicos e literários sobre trauma surgiram no contexto das reflexões sobre o Holocausto, situação considerada como um contexto clássico de terror e sobrevivência. A tendência dos estudos, nos últimos dez anos, tem revelado um alargamento das reflexões para outros contextos como, por exemplo, para os contextos das sociedades coloniais e pós-coloniais em que são muito frequentes traumas relacionados com sentimentos de perda, abandono, rejeição, traição, racismo, entre outros ${ }^{19}$. A mudança de paradigma nesta área de pesquisa fez com que, para além de uma dimensão psicanalítica (assente no pensamento de Freud e seus seguidores), fossem integradas também as perspetivas psicológica, sócio-histórica e cultural. Outro aspeto importante na diversidade de estudos que têm surgido é o reconhecimento de que existem diferentes tipos de trauma, bem como diferentes formas de as pessoas se relacionarem

18 Leia-se: "Eu andava a escrever uns versos desligados, palavras que rimavam umas com as outras, fios de histórias que não tinham princípio nem fim, cenas, apenas cenas, todas elas inconsequentes, se resumidas por palavras dignas. E no entanto, elas viviam em mim com naturalidade e saíam-me pelos dedos com a simplicidade com que a saliva sai da boca, a bílis do fígado. Era uma secreção biológica, uma substância carnal” (141).

19 Traumas que alguns autores têm chamado de "quite traumas" (T. M. Luhrmann), "common traumas" (D. Barrett) ou "family traumas" (Ann Kaplan). 
com essa multiplicidade de eventos traumáticos. Pode, por um lado, experienciar-se trauma como vítima (individual ou coletiva), isto é, de uma forma direta ou, por outro lado, de forma secundária, como pessoa próxima da vítima, próxima de uma situação de catástrofe ou, simplesmente, próxima por empatia, através da leitura, da audição ou da visualização de situações violentas e, potencialmente, traumáticas.

Seguindo esta ordem de ideias, a experiência traumática de Solange Matos é um pouco complexa de caracterizar, já que ela não se apresenta propriamente como a vítima do evento traumático que a persegue, mas também não se apresenta como completamente próxima da vítima; talvez por ser muito jovem quando as circunstâncias descritas ocorrem, não há, no imediato, a expressão direta da sua compaixão e empatia pelo protagonista daquele episódio na estrada do Gurué ${ }^{20}$. Solange dá-nos conta daquele evento como observadora exterior, mas uma observadora que sente e carrega a violência das intenções e dos atos do pai, violência que poderá remeter para a violência simbólica do colonizador sobre o colonizado. Em última análise, porém, as mãos do jovem negro são como que uma parte das mãos de Solange, já que esta carrega consigo a história da sociedade portuguesa e o seu passado de violência colonial. Solange, tal como as outras jovens, é um "dos pedaços de um velho império perdido" (17). O trauma individual de Solange provocado por esse evento na estrada do Gurué adquire, ao longo da narração, um valor de trauma coletivo, na medida em que despoleta uma reflexão crítica sobre as relações entre colonizadores e colonizados, a violência e o medo decorrentes da guerra colonial (ou pela independência) e a fuga apressada dos colonos a partir de 1974. Na nota introdutória do romance intitulada "Sobre este livro" e assinada por LJ (as iniciais da autora), reitera-se justamente a ideia de que os traumas individuais participam e enformam os traumas de uma comunidade: "na história de um bando conta-se sempre a história de um povo" $(9)^{21}$.

A “experiência de várias gerações de portugueses em África” é representada de forma magistral no episódio do jantar no restaurante Ritornello. Jantar a que Solange se sente obrigada a comparecer para representar e assinar o nome da família num abaixo-assinado em defesa dos direitos dos "regressados" a uma indemnização pelos bens materiais deixados em África. Embora o pai de Solange não acreditasse que o protesto surtisse efeitos positivos, Solange cumpriu a vontade do pai de ser solidário com os amigos e conhecidos. O nome do restaurante é, desde logo, extremamente expressivo. Ao remeter para as repetições musicais nas óperas barrocas, o "pequeno retorno" que o nome invoca combina com o ambiente de revivalismo que se vive ao longo do jantar. Aos

20 A manifestação de empatia talvez seja impedida pela possibilidade de "o aluno dilecto" não estar simplesmente buscando a própria sobrevivência, mas antes exercer violência sobre a família de colonos. 21 Ainda que não aborde questões de trauma, Maria Graciete Besse vai ao encontro desta linha de análise, num artigo publicado em novembro de 2013. 
olhos da jovem Solange, as pessoas presentes naquele convívio não passam de "uma assembleia de velhos regressados de um tempo de que não havia retorno" (35), a desadequação dos modos e do vestuário ao local e à circunstância colocam aquelas pessoas "fora do tempo", evocando sentimentos de derrota. O espectro de experiências e sentimentos deste grupo de pessoas é expresso através de um objeto do quotidiano - as toalhas adquirem os sentimentos das pessoas reunidas nas mesas, que tanto podem ser de nostalgia e saudade, vingança e esperança, como de ódio, ironia, sarcasmo e humor. A antropomorfização das toalhas exprime a ligação invisível entre todas aquelas pessoas, assim como realça a "toada de morrer" que sai da voz das irmãs Alcides. Como pano de fundo, paira sobre a sala "a representação de uma pacaça em tamanho natural e um caçador furtivo apontando-lhe ao lombo, enquanto os filhotes corriam até às margens do quadro. Era muito claro que a pacaça lançava para o meio da sala um olhar humano" (35). E era muito claro também que esse olhar humanizado do mamífero remetia para a lógica de valores típica dos predadores coloniais, lógica que não agradava às irmãs Alcides que confessam a Solange detestar "os olhos da pacaça e aquele ambiente mórbido" (42). As óperas que as sopranos eram impelidas a cantar acorrentavam-nas ao mundo do passado, do qual estas desejavam libertar-se.

Dando exemplo de eventos traumáticos diversos (como guerras civis, Holocausto entre outros), LaCapra explica que através de uma experiência traumática uma pessoa constrói uma identidade que é ao mesmo tempo individual e coletiva (cf. 2001: 162). A proposta narrativa de Lídia Jorge corrobora justamente a explicação de LaCapra. A experiência de Solange Matos, assim como a experiência coletiva do grupo das cinco cantoras presta-se a uma leitura nacional sobre a experiência histórica do povo português. De facto, para além de uma reflexão mais universal em torno da cultura do espetáculo e do sensacionalismo dos meios de comunicação social, os tópicos de reflexão que sobressaem relacionam-se com o fim do império colonial, o reajustamento às fronteiras europeias, a democratização e a adesão à Comunidade Europeia, a receção da população “retornada”, as diversas experiência de integração desta população na sociedade portuguesa e ainda as vivências dos imigrantes em Portugal, nomeadamente os provenientes das ex-colónias, como é o caso da família de Madalena Micaia. África é, como diz Solange, o "elo de distância" (57) que unia aquela banda em formação.

Madalena Micaia (repare-se que o sobrenome designa uma árvore africana de grande porte) é uma figura singular e a sua morte é um dos eventos mais significativos para uma compreensão global da proposta de reflexão apresentada por Lídia Jorge. Sendo a cantora mais talentosa do grupo, Madalena Micaia torna-se indispensável para a sobrevivência dos sonhos de Gisela (e das restantes três jovens). A voz jazzística da jovem africana é a melhor voz do grupo e, por isso, a mais importante de todas e sem a qual a sobrevivência da 
banda é posta em causa. O talento indispensável de Madalena Micaia pode curiosamente lembrar a importância das colónias para Portugal e a ideia de que sem elas Portugal não sobreviveria economicamente. Dada a imprescindibilidade de uma voz forte no grupo, Gisela (e metaforicamente a indústria do espetáculo) exerce uma pressão fortíssima sobre Madalena Micaia, tanto pressão para emagrecer, quanto para ser pontual e assídua aos ensaios, assim como para não perder tempo com relações amorosas. A atitude coerciva da "maestrina" vai forçar a cantora a omitir, num primeiro momento a gravidez e, num segundo momento, o dia do nascimento do filho. Sendo que esta última omissão leva Madalena a comparecer a um ensaio três dias depois de ter dado à luz e, consequentemente, a falecer por exaustão em plena garagem.

Madalena Micaia é a grande vítima do crime de Gisela - o crime do individualismo, da prepotência do poder e do dinheiro, da cegueira da fama, dos caprichos individuais, da falta de solidariedade e empatia. Perante a morte de Madalena, Solange e as irmãs Alcides não são menos culpadas. Solange, inclusivamente, partilha com Gisela a verdade do que aconteceu naquela tarde fatídica, isto é, a verdade sobre o fim que o corpo de Madalena Micaia teve, fim que nunca foi investigado e que acabou por cair em esquecimento. Se esses acontecimentos não perturbam emocionalmente Gisela por muito tempo, o mesmo não acontece com Solange. Na verdade, à semelhança da imagem do jovem agarrado ao camião em fuga, a morte de Micaia acaba por perseguir a letrista inevitavelmente. Essa morte é sentida como um crime do qual não pode deixar de se sentir cúmplice, por isso, Solange não consegue no imediato dos acontecimentos "afastar a imagem de Madalena Micaia", mesmo que tenha tudo "para não precisar de continuar fixada naquele acontecimento da garagem” (238). Uma vez mais, no percurso de Solange duas realidades opostas e inconciliáveis ocupam os seus pensamentos - a morte e a vida ${ }^{22}$.

Vítima da pravidade e da violência que decorrem do excesso de vontade e poder de Gisela, Madalena Micaia é também vítima de racismo e de exclusão social. O trabalho no restaurante e os sacos de plástico que a cantora traz sempre consigo são um sinal evidente de um dia a dia precário, uma vida de esforço e de sobrevivência. Micaia ganha o sustento da família, como ela própria explica: "Se chego atrasada é por causa da vida da família, pai, mãe, todos sem nada, depois daquela calema que lhes levou a casa, naquela costa de São Tomé. E agora até o meu irmão chegou a Lisboa e também não tem casa. Ando a tratar da vida dele. O que é que eu posso fazer?” (171). À falta de dinheiro, acresce tanto a falta de solidariedade para com esta jovem que ninguém procura verdadeiramente conhecer (nem o dono do restaurante, nem

22 Leia-se: "O que eu queria era poder contar a João de Lucena o que se passou na garagem, mas não posso. (...) Eu não falo do sucedido, não só porque não devo, mas também porque não quero que se misturem no meu pensamento duas realidades opostas - A morte que levou a Micaia dentro de uma carrinha, e a vida que irradia de uma pessoa chamada João de Lucena” (239). 
as companheiras da banda sabem, por exemplo, onde ela mora $)^{23}$, quanto o racismo de que é alvo por ser negra. Esse racismo é expresso, por exemplo, pelo uso do verbo parir nas observações do maestro Capilé sobre a gravidez da jovem cantora (177) ou pelo comentário de Julião Machado sobre a possível ausência desta no palco: "De vista não faz falta nenhuma. Até destoa, cria um acidente antropológico, desnecessário” (213). A este propósito, é também importante assinalar as observações feitas por estes dois homens sobre a maneira como os africanos lidam com o tempo cronológico ou encaram as dinâmicas familiares. No momento em que a banda e os seus promotores debatem o que fazer com a ausência da melhor voz do grupo, emergem na narrativa a dificuldade de se lidar com a diferença, os choques culturais e os preconceitos relativamente ao Outro - o africano, o negro. E, neste sentido, a narrativa expõe as dificuldades que uma sociedade ex-colonial tem em gerir e aceitar, sem excluir, a heterogeneidade e a diversidade cultural dos seus cidadãos e dos seus imigrantes.

A morte de Madalena Micaia faz com que, pela primeira vez, se entreveja nesta narrativa um vago sentimento de solidariedade que proporciona um momento de partilha entre as quatro jovens nascidas em África. Silenciada a voz do elemento mais frágil (o negro, o subalterno, o colonizado) através da exclusão e da morte, as histórias que se partilham são as das descendentes do império colonial e, por extensão, as histórias dos colonizadores, dos colonos, dos portugueses brancos com ligações a África, grupo que no seio da sociedade portuguesa ex-metropolitana foi também alvo de exclusão social no período que se seguiu à sua chegada a Portugal ${ }^{24}$. Reconhecendo que a morte de Madalena Micaia caiu no esquecimento, sobretudo porque a circunstância da sua morte foi reduzida a factos incompletos de modo a evitar-se a atribuição de culpas e a descoberta da verdade, Solange relata o momento em que as quatro jovens nascidas em África desenterram o seu passado africano. Sabe-se então, pela primeira vez, que a Casa Paralelo pertencia a um proprietário de roças de café arábico que nos anos cinquenta tinha prosperado nas terras de Cuanza-Sul. Sabe-se também que as irmãs Alcides tinham, em 1975, fugido num jipe, pela rota do Lobito, trazendo apenas algumas roupas e um saco de mantimentos, dentro do qual estava um pão endurecido cujo recheio era um punhado de diamantes postos lá pela cozinheira negra, sabe-se ainda que os

23 A ausência de laços de afeto, de solidariedade e de comunicação entre as cinco jovens perpassa toda a história e é visível no facto de, por exemplo, não se despedirem quando saem dos ensaios, indo cada uma à sua vida (78), mas também no facto de não saberem quase nada da vida quotidiana umas das outras, nomeadamente o de não saberem onde as outras moram (195). Solange só explica que mora numa hospedaria com vários estudantes passados vários meses de ensaios (150). Depois da morte de Madalena Micaia e de Solange descobrir subitamente que João de Lucena era homossexual, Solange visita a Casa Paralelo e o seu comentário inicial não podia ser mais ilustrativo da falta de solidariedade e afeto que reinava naquela garagem: "Estava ali porque queria vê-la. Só isso. Tanto encontro, tanta fala, e nunca tinha conhecido Gisela Batista. Pois agora eu só vinha confirmar que tudo possuía uma outra face. Gisela também” (286).

${ }^{24}$ A este respeito, leia-se, na página 40, a "lenda negra" que foi criada à volta do regresso da família Alcides. 
pais tinham falecido num acidente quando, anos mais tarde, voltaram a Angola para matar saudades. De Gisela sabe-se apenas que o seu pai morreu em solo do Cuanza e que ela e a mãe partiram em direção a África do Sul depois de esta ter conhecido o Senhor Simon - o dono da construtora que recupera a Casa Paralelo e padrasto-protetor-amante de Gisela.

No que diz respeito à narradora, o leitor vê neste momento de partilha, pela primeira vez, uma possibilidade de "working-through" relativamente à sua experiência traumática, mesmo que essa tentativa decorra de um impulso inconsciente. De facto, o luto imposto pela morte de Madalena Micaia e a urgência de um momento de genuína partilha entre aquelas jovens faz com que, pela primeira vez, Solange fale das imagens que, agarradas ao corpo, a perseguem. Porque simboliza todo o passado de violência colonial, a morte da cantora africana despoleta uma revisitação da memória. O que Solange e as outras jovens choram não é propriamente a morte de Micaia e o esquecimento de que esta é alvo, mas o seu próprio passado individual e coletivo. A empatia que potencialmente existia perante a trágica morte da cantora africana transforma-se em sentimento de perda individual. No fundo, estas jovens choram a sua própria experiência como pertencentes a uma sociedade de violência e desconfiança.

Feitas estas confissões, é Gisela quem faz o balanço sobre os acontecimentos relacionados com a morte de Madalena Micaia, expondo as fragilidades de uma sociedade que tem dificuldades em lidar com o passado:

Já todos fizemos as pazes uns com os outros, há tantos anos, que este episódio que nos aconteceu aqui dentro mais parece um fantasma vindo do futuro. Mas aposto que, se alguns soubessem desta tragédia, ainda haveria quem dissesse que foi uma história de vingança entre colonos e colonizadores. Tudo termina em canções? Não, infelizmente, tudo termina em clichés. Vocês são testemunhas de que foi apenas uma história de gente, a história de um grupo vítima de uma mulher estúpida e sem escrúpulos, e essa mulher sou eu... (233)

O facto de ser Gisela a fazer este balanço não parece ser gratuito. Exercendo ela as pressões do mundo impessoal e material do espetáculo e tendo sido ela o principal promotor da violência exercida sobre Madalena Micaia ${ }^{25}$, o que Lídia Jorge parece querer é obrigá-la a fazer um ato de mea culpa, apontando os efeitos nocivos da falta de solidariedade e respeito pelo Outro numa sociedade que se deixa reger pela "lógica da garagem", a lógica do império minuto (308). Neste contexto, fazem todo o sentido as palavras de Maria Graciete Besse sobre

25 Note-se que Solange se refere a Gisela, desde o momento em que a conhece, como "torturadora", tendo em conta o fascínio e o poder que esta exercia sobre as outras. Há vários exemplos das atitude coercivas de Gisela, por exemplo, quando Gisela interroga Nani Alcides sobre o seu envolvimento com o rapaz da Kawasaki (165-166), quando Gisela bate em Madalena Micaia e a expulsa da garagem, depois de descobrir que esta estava grávida (174-175), quando, evitando que Micaia engordasse, a impede de comer uma banana (217) e, ainda, quando Gisela vaticina - parodiando o discurso religioso - o futuro de desgraça que vai cair sobre a cantora africana (186). 
este romance, “A tensão entre a lembrança e o esquecimento remete assim para diferentes níveis de significação da história, evidenciando tanto questões políticas como morais, sempre identificadas com espaços de grande violência física e psicológica onde Lídia Jorge inscreve uma exigência ética e a necessidade de reinventar a dignidade humana” (2013: 126).

O percurso de Solange Matos parece ser o de uma geração à deriva, uma geração que não conseguiu desprender-se do passado e que é condicionada por esse passado, porque não o entende e/ou não é capaz de o superar. O tom das últimas páginas do seu relato é de um verdadeiro desalento. A impossibilidade de ter o amor de Lucena, o corte afetivo com os pais e o envolvimento com o tio de José Alexandre, onde o amor parece não existir, provam que a nova vida ambicionada por Solange, nos finais da década de 80, não se concretizou. Tal como as irmãs Alcides que falharam acomodando-se a casamentos convencionais, também Solange se acomodou ao silêncio e, de certa forma, falhou. A alternativa ao comodismo das irmãs Alcides e de Solange, é o perigo que Gisela representa. No entanto, a descoberta que Solange faz no final do seu relato é de que a própria Gisela está votada fatalmente ao esquecimento porque vive dentro da "engrenagem que mais rapidamente faz esquecer" (316). Ou seja, "a força obscura” de que Gisela corre atrás é destrutiva e efémera. À parte de tudo isto, encontra-se o mundo da razão e o furioso ativismo de Murilo. Mas deste mundo, Solange está ainda mais afastada. Na nossa leitura, não existem na narração indícios de que Solange consiga, de facto, transcender o processo de "acting-out" construindo a possibilidade de um futuro não maculado, de certa forma, pelos traumas do passado. O ataque de choro que Solange tem depois de ouvir as irmãs Alcides a cantar num anfiteatro da universidade é relevador do peso geracional carregado por estas jovens, peso que se transforma num fardo difícil de suportar: "comecei a chorar à socapa para dentro de um lenço. Até que os meus ombros me traíram chorando também. Provavelmente, chorava por elas em mim, como acontece em semelhantes casos. A minha ideia, porém, é que chorava de vergonha de todos nós na pessoa das sopranos, ainda que não quisesse admitir o que nisso havia de lástima" (41).

Se Solange não consegue, individualmente, levar a cabo o processo de "working-through" necessário para compreender e contextualizar as imagens traumáticas do passado, Lídia Jorge propõe que esse trabalho seja feito através da leitura como prática ética, um tipo de leitura em que o leitor terá naturalmente de questionar a sua consciência histórica. Tal como Laurie Vickroy salienta, "The nature of these narratives encourages readers to become more aware, to adopt a new consciousness of history, even if it is one that is fragmented, ambivalent, and at times inconclusive" $(2002: 33)^{26}$. Neste âmbito, é impor-

26 Tradução: "A natureza dessas narrativas incentiva os leitores a se tornarem mais conscientes, a adotarem uma nova consciência da história, mesmo que seja fragmentada, ambivalente e, às vezes, inconclusiva." 
tante também notar que LaCapra se baseia no conceito de "working-through" para descrever o papel dos textos literários na representação do trauma, argumentando que a escrita implica, necessariamente, alguma distância da situação traumática e é um processo inerentemente terapêutico. Com efeito, Lídia Jorge instiga-nos a não esquecermos o nosso passado coletivo e a revisitá-lo para criarmos possibilidades de um presente e de um futuro mais solidários e justos. O registo escrito dessa revisitação (a que a citação que colocamos em epígrafe alude) é a sua notável contribuição. Os autores que estudam as questões relacionadas com o trauma defendem que para haver um verdadeiro caminho para a cura é necessário que os sobreviventes contem as suas histórias e que sejam reconhecidos e aceites. É este trabalho de contar que Lídia Jorge faz neste romance e, esse trabalho adquire uma enorme importância na revisitação da história portuguesa e, consequentemente, na construção de uma sociedade mais consciente.

\section{Referências}

BESSE, Maria Graciete (2013), "Memória, empoderamento e ética na obra de Lídia Jorge”, Revista do Núcleo de Estudos de Literatura Portuguesa e Africana da UFF, 5 (11): 117-134.

CARUTH, Cathy (1995), Trauma: Explorations in Memory. Baltimore: Johns Hopkins UP.

CARUTH, Cathy (1996), Unclaimed Experience: Trauma, Narrative, and History. Baltimore: Johns Hopkins UP.

JORGE, Lídia (2011), A noite das Mulheres Cantoras. Lisboa: Dom Quixote.

KAPLAN, E. Ann (2005), Trauma Culture: The Politics of Terror and Loss in Media and Literature. New York: Rutgers University Press.

LACAPRA, Dominik (2001), Writing History, Writing Trauma. Baltimore: Johns Hopkins University Press.

LACAPRA, Dominik (2004), History in Transit: Experience, Identity, Critical Theory. Ithaca, NY: Cornell University Press.

MEDEIROS, Paulo de (2012), "Literatura, memória, resistência: breves apontamentos em tempo de crises”. Navegações, 5 (2): 218-227.

SCARRY, Elain (1985), The Body in Pain: The making and unmaking of the world. New York: Oxford University Press.

VICKROY, Laurie (2002), Trauma and Survival in Contemporary Fiction. Charlottesville: University of Virginia Press.

WIMMERS, Inge Crosman (2003), Proust and Emotion: The Importance of Affect in "A la recherche du temps perdu". Toronto: University of Toronto Romance Series.

WHITEHEAD, Anne (2004), Trauma Fiction. Edinburgh: Edinburgh University Press.

Submetido: 10-12-2015

Aceite: 26-05-2016 